\title{
Correction to: ASO Author Reflections: Minimally Invasive Esophagectomy for Esophageal Cancer in the Prone and Lateral Position
}

\author{
Susumu Miura, MD, and Yoshihiro Kakeji, PhD, MD
}

Division of Gastrointestinal Surgery, Department of Surgery, Graduate School of Medicine, Kobe University, Kobe, Hyogo, Japan

\section{CORRECTION TO:}

ANN SURG ONCOL (2020) 27:691

HTTPS://DOI.ORG/10.1245/S10434-019-08034-Y

This article is a duplicate publication. It was originally published under https://doi.org/10.1245/s10434-019-0799 7-2.

The original article can be found online at https://doi.org/10.1245/ s10434-019-08034-y.

(C) Society of Surgical Oncology 2020

Published Online: 28 July 2020

S. Miura, MD

e-mail: smiura@med.kobe-u.ac.jp 